\title{
ANOMALOUS RADIOCARBON DATES FROM EASTER ISLAND
}

\author{
Kevin Butler ${ }^{1,2}$ • Christine A Prior ${ }^{3}$ John R Flenley ${ }^{1}$
}

ABSTRACT. The largest volcanic crater on Easter Island in the South Pacific contains a lake $1 \mathrm{~km}$ in diameter with large floating mats of vegetation, mainly Scirpus californicus. A core taken through a mat near the center produced anomalous dates, with older dates above younger ones. The possibility that the mat had become inverted was considered, but palynological evidence refutes this idea because it shows a progressive upward decline of forest pollen, which is well known from other swamp cores on the island. A new series of radiocarbon dates made directly on pollen concentrates was obtained. These dates also produced inconsistencies, particularly when pollen concentrate ages were compared with ${ }^{14} \mathrm{C}$ ages on plant fragments from the same depth. This series of ${ }^{14} \mathrm{C}$ ages seems to indicate that both old and young organic components in the sediment are deposited contiguously and that the depositional history of these cores is more complex than previously known. Previous age determinations on bulk sediments from Easter Island, which also show anomalous dates, may be too simplistic. This paper provides a warning to other researchers dating sediments from Easter Island. We suggest that sample selection and dating procedures be carefully considered for these sediments.

\section{INTRODUCTION}

Easter Island has been the subject of much research and speculation in recent years. Palynological evidence clearly shows that Easter Island, for at least the past 35,000 yr, was extensively forested, mostly by a now-extinct palm. Travellers to the island in recent times, however, are greeted by a landscape of grasslands where the much admired statues, or Moai, far outnumber the few scrubby trees present. Deforestation occurred mostly between AD 700 and AD 1680, which is within the accepted time of human occupation. Most debate and controversy occurs concerning the causal factors leading to the disappearance of the forest and rapid decline of the society. Flenley et al. (1991), Bahn and Flenley (1992), and Flenley and Bahn (2003) argue that the collapse of the Easter Island economy and the severe decline in its population were caused primarily by exhaustion of the island's resources, principally its timber resource. McCall (1993) has speculated that these major changes resulted from a severe drought induced by the Little Ice Age. Hunter-Anderson (1998) has totally dismissed the "human impact scenario," claiming the decline of forest was the sole result of climate change. If the disagreement between the "human impact" and "climate change" hypotheses is to be resolved, then a high-resolution chronology of vegetational change on Easter Island must be obtained.

Easter Island is volcanic in origin, roughly triangular in shape, and covers an area of $117 \mathrm{~km}^{2}$ (Figure 1). The landscape is dominated by the 3 volcanic peaks which give the island its triangular shape. The coastline is mostly rugged with few sandy beaches. The nearest inhabited landmass is Pitcairn Island, some $2092 \mathrm{~km}$ to the west, and the nearest continental landmass is South America, $3599 \mathrm{~km}$ to the east. This makes Easter Island one of the most isolated places to live on this planet. The isolation is probably partly responsible for the extremely depauperate flora, with less than 50 vascular species known from the island.

Sediment from the 3 swamps/lakes on Easter Island has been the subject of palynological analysis. Flenley et al. (1991) describe the vegetational history from cores taken in Rano Raraku and Rano Aroi, and at the edge of the Rano Kao caldera. Dating of sediments from these 3 sites was performed by the Scottish Universities Research and Reactor Centre (SURRC). The age-depth graphs pro-

\footnotetext{
${ }^{1}$ School of People, Environment and Planning, Massey University, Palmerston North, New Zealand.

${ }^{2}$ Corresponding author. Email: K.R.Butler@massey.ac.nz.

${ }^{3}$ Rafter Radiocarbon Laboratory, Institute of Geological \& Nuclear Sciences, Lower Hutt, New Zealand.
}

(C) 2004 by the Arizona Board of Regents on behalf of the University of Arizona Proceedings of the 18th International Radiocarbon Conference, edited by N Beavan Athfield and R J Sparks RADIOCARBON, Vol 46, Nr 1, 2004, p 395-405 
duced show a relatively good fit with the dates, but a number of anomalous dates do occur. From the Rano Raraku sediments, 10 bulk samples were submitted for dating. Of these, three seem too old and one appears too young. The possibility of contamination by inwashed soil carbon was suggested for some of these anomalies. Eleven bulk sediment samples were submitted from Rano Aroi, of which one in the top meter was much too old. The upper $\sim 1 \mathrm{~m}$ of these sediments has been severely disturbed during the building of a small dam in the 1920s. Flenley et al. (1991) considered that some of the older dates from Rano Aroi appear younger than expected and suggest the possibility of young roots from above contaminating the older sediments. Five bulk sediment samples were submitted from Rano Kao (borehole 1). One date appeared much too young. In this case, young roots from above were offered as a possible explanation. Flenley et al. (1991) also report observing an inversion of a smaller, modern floating mat on Rano Kao during field work.

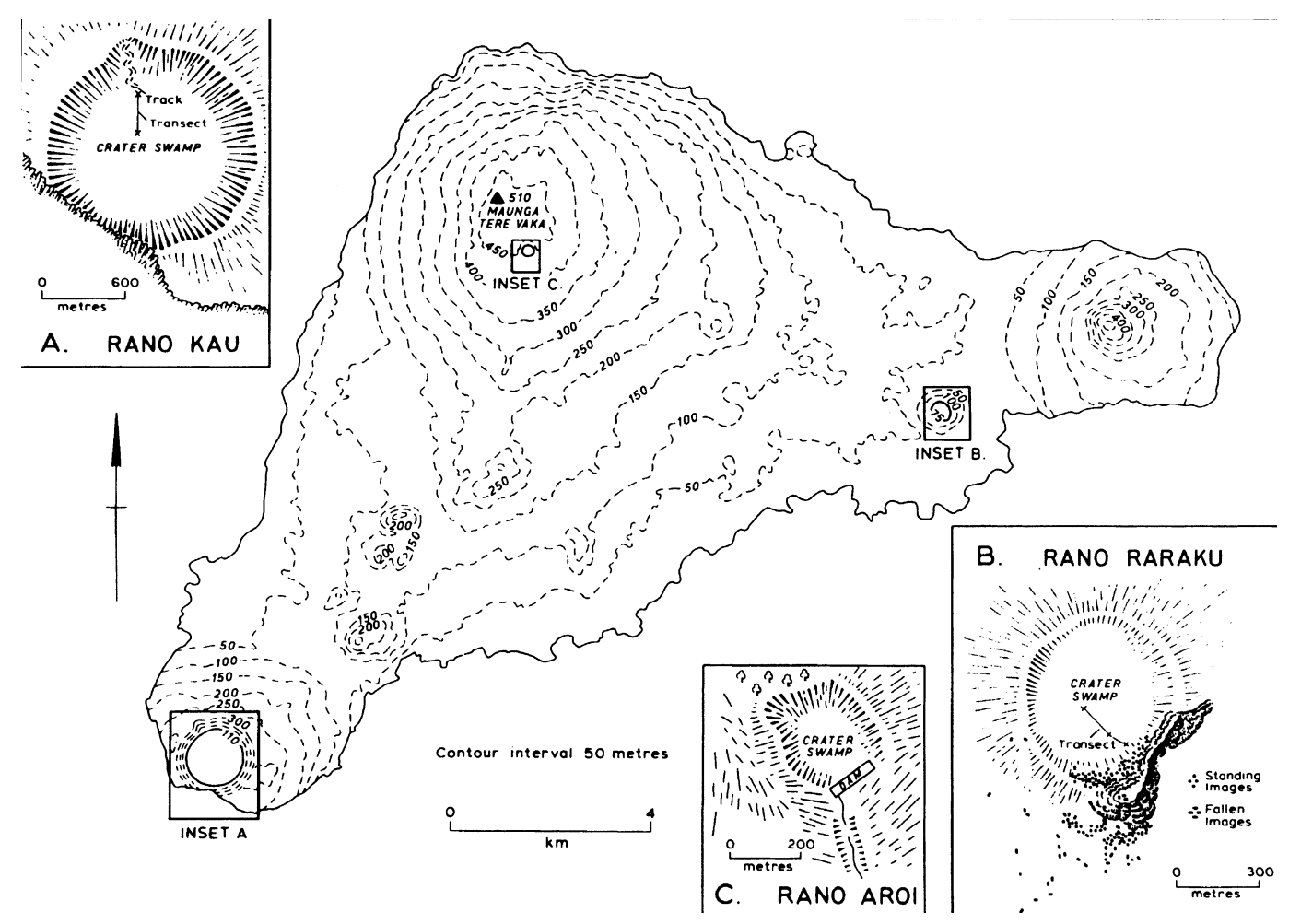

Figure 1 Map of Easter Island. Inserts show the 3 coring sites. Rano Kao (Kau) borehole 2 (near the center of the crater), which is the focus of this paper, is shown in insert A.

\section{METHODS}

\section{Site Description and Coring}

This paper describes a second sediment core recovered from nearer the center of Rano Kao in 1984. Preliminary work on this core (borehole KAO 2) was reported in Flenley (1996) and Butler and Flenley (2001). Rano Kao is a collapsed crater (caldera) almost circular in shape, located in the southwest part of the island. The inner walls slope down at an angle of about $30^{\circ}$ to a circular floating swamp about $1 \mathrm{~km}$ in diameter. The swamp surface consists of several floating mats of various sizes and thicknesses, which occupy large areas, although open water does exist between the float- 
ing mats. The dominant species on the floating mats is the totora reed, Scirpus californicus. An interesting feature of this vegetation is the apparently dead patches found in the center of some of the larger floating mats.

Borehole 2 (KAO 2) was extracted using a Russian D-section corer (Jowsey 1966), approximately $300 \mathrm{~m}$ in from the eastern edge. The core consists of 2 separate parts, $3 \mathrm{~m}$ of floating mat and $10 \mathrm{~m}$ of lake sediment, the 2 parts being separated by $8 \mathrm{~m}$ of water. Unfortunately, coring could not proceed past this point due to insufficient extension rods being available for the corer. The stratigraphy of the core is fairly uncomplicated. The 3-m floating mat consists of very soft, coarse organic detritus with rhizomes of Scirpus californicus in the uppermost meter. The lake sediment consists entirely of coarse organic detritus, although the lowest $15 \mathrm{~cm}$ was darker and more consolidated than that above. The 2 parts of this core were sampled for palynological analysis at $10-\mathrm{cm}$ intervals. The vegetation patterns of the resulting pollen diagrams reinforced the findings of the previous pollen diagrams from Rano Raraku and Rano Aroi. In general, a 3-zonal pattern of vegetation exists. The lower zone is dominated by trees and shrubs with Palmae being predominant. Ferns are variable in abundance and Poaceae are virtually absent. The middle zone shows a steady, but sometimes sawtoothed, decline in trees and shrubs. Ferns are abundant and Poaceae become prominent. Charcoal particles appear in significant quantities. In the upper zone, trees and shrubs decline and disappear. Ferns and Poaceae dominate completely and charcoal is abundant. A summary diagram of the Rano Kao 2 pollen profiles is provided in Figures 2 and 3. For the full pollen diagrams, see Butler and Flenley (2001).

\section{Dating}

Initial dates from the KAO 2 cores were accelerator mass spectrometry (AMS) dates on bulk sediment obtained from Nagoya University and reported in Flenley (1996). In an attempt to establish a preliminary chronology, 5 sediment samples were measured. With the exception of NUTA-3516, these initial dates seem to fit expectations once compared with the data from Flenley et al. (1991), considering the few pollen samples analyzed at that time (samples were taken at 50 -cm intervals). Once the pollen analysis (sampling at 10 -cm intervals) was completed some years later, it was decided to obtain additional ${ }^{14} \mathrm{C}$ analyses. A new method of AMS dating of pollen concentrates had been developed at the Rafter Radiocarbon Laboratory and this was considered an ideal opportunity to compare ages from pollen concentrates with the original bulk sediment ages.

Sediment from several depths in KAO 2 were treated for pollen separation and concentration by the method described in detail in Prior and Chester (2001) and Vandergoes and Prior (2003). After chemical pretreatment with $\mathrm{HCl}, \mathrm{HF}, \mathrm{HNO}_{3}$, and ammonia solution, the samples were sieved and then subjected to a density separation with sodium polytungstate (SPT). The samples were centrifuged with SPT solutions of decreasing specific gravity, with the precipitates of each centrifugation saved as separate fractions. Individual fractions were examined under the microscope and those containing the highest pollen concentrations were selected for combustion and dating. These pollen fractions are identified in Table 1 by the specific gravity at which they precipitated. At 2 depths, 16.75-16.85 m and 18.25-18.35 m, 2 additional fractions were dated for comparison: large plant fragments $(\sim 1 \mathrm{~mm})$ sieved from the sediment and a different density fraction containing fine plant debris but no pollen.

In an experiment to determine whether Rano Kao showed evidence of a reservoir effect, we also dated several fractions from the top $7.5 \mathrm{~cm}$ of the floating mat. The original material removed in taking this core consisted of mostly basal stems and roots of Scirpus californicus and a smaller component consisting of plant fragments, mineral, and charcoal. Dating of this material was expected to 


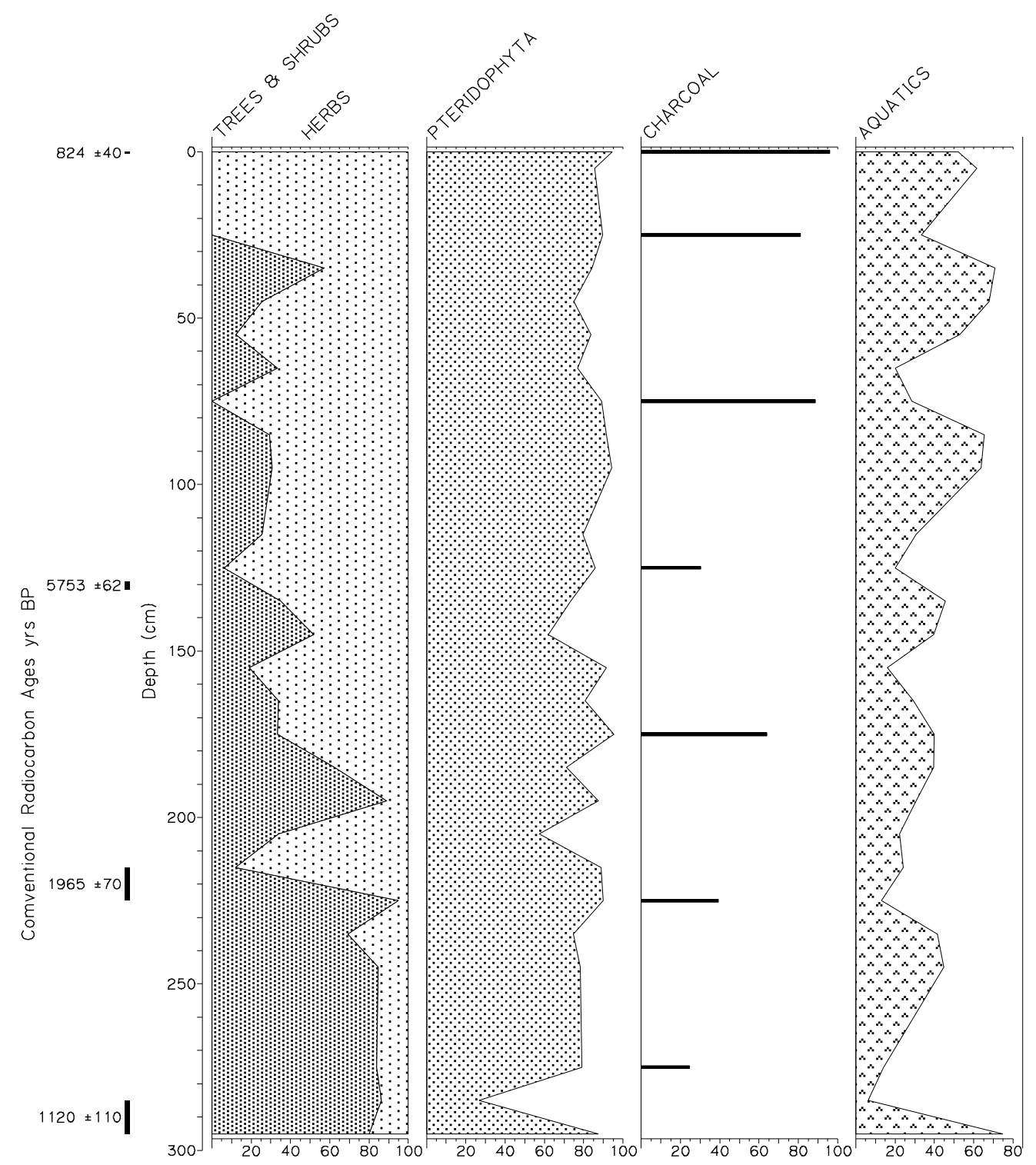

Figure 2 Summary pollen profile for the Rano Kao floating mat. The ages given are for bulk sediment dates when these were the only ages available, else ages are those obtained from AMS dating the specific gravity separation containing pollen and spores. 


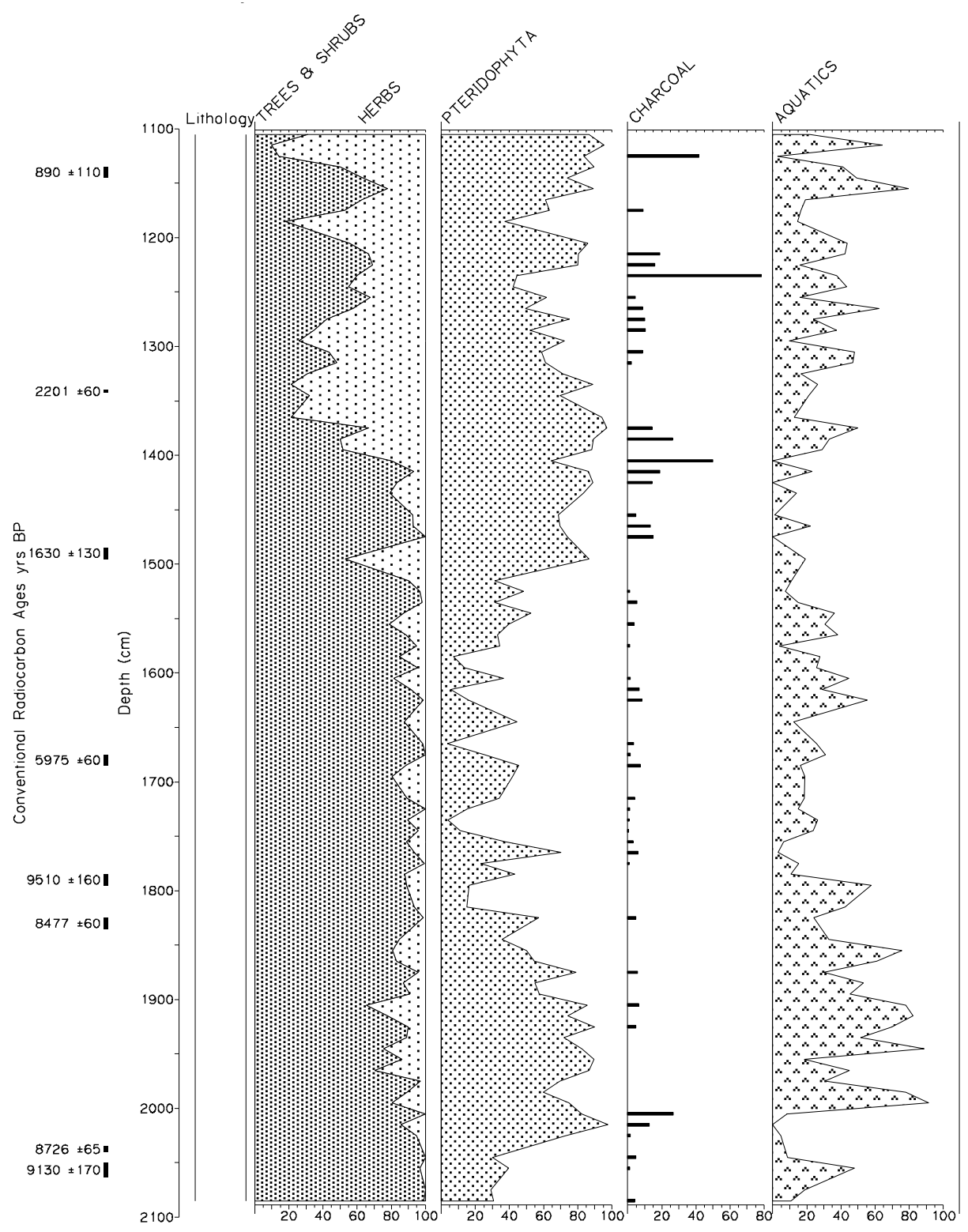

Figure 3 Summary pollen profile for the Rano Kao lake sediment. The ages given are for bulk sediment dates when these were the only ages available, else ages are those obtained from AMS dating the specific gravity separation containing pollen and spores. 


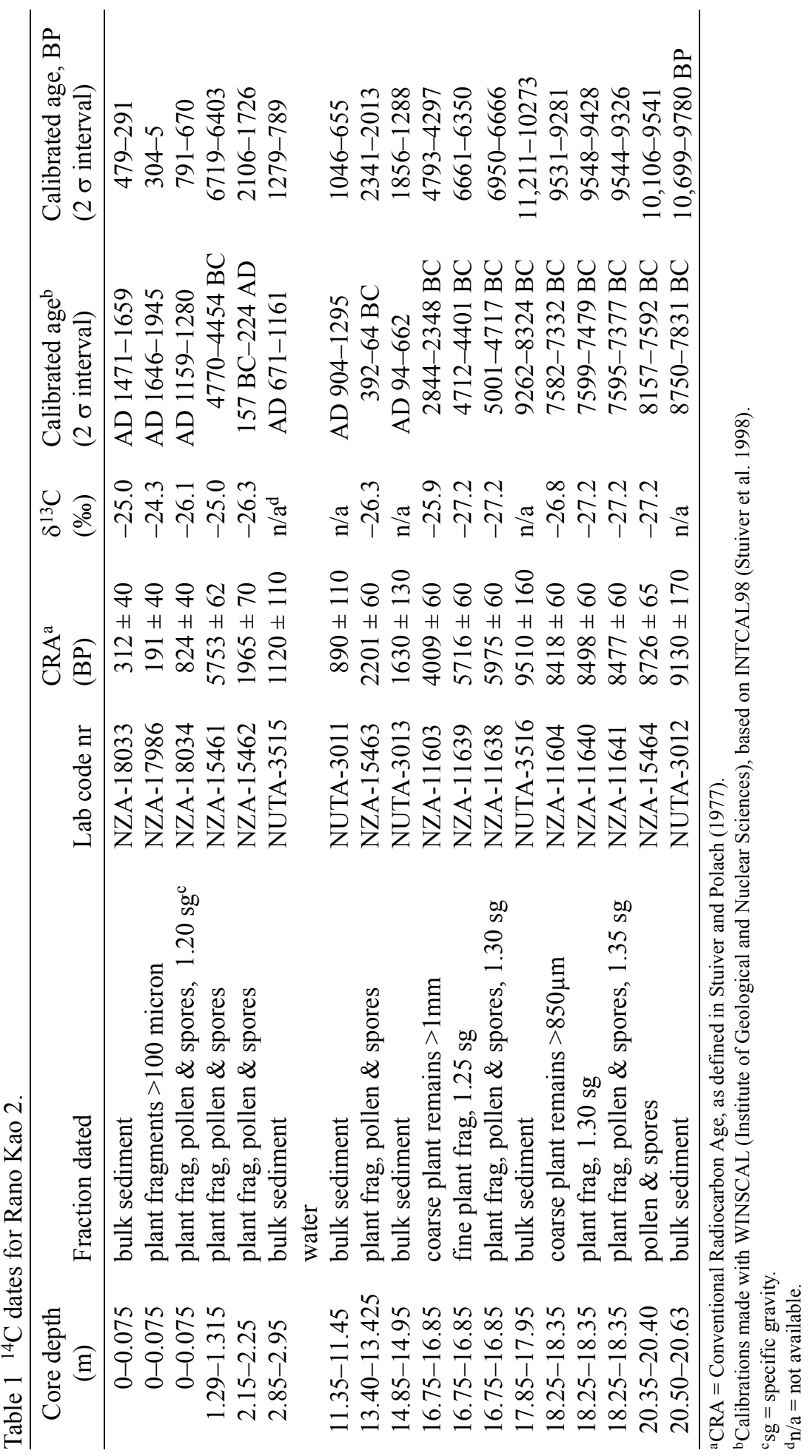


return ages no older than $150 \mathrm{yr}$. The upper $7.5 \mathrm{~cm}$ was split longitudinally into 2 equal parts. One half remained intact and was dated as a "bulk sediment" sample, receiving a standard acid/alkali/ acid pretreatment. This "bulk" sample contained all the constituent parts of the original material. The other half was treated to separate a pollen concentrate as described above. Two fractions from this procedure were chosen for dating: large plant fragments $>100$ microns and the plant fragments, pollen, and spores that precipitated at a specific gravity of 1.20 .

Results for all of the ${ }^{14} \mathrm{C}$ age analyses are presented in Table 1. Nagoya University ages are identified by the NUTA laboratory code and Rafter Radiocarbon Laboratory ages are identified by the NZA lab code.

\section{RESULTS}

The depths in KAO 2 chosen for dating by the pollen concentrate procedure were selected to elucidate some age inversions which appeared in the suite of ages from Nagoya. The base of the floating mat at 2.85-2.95 m produced an age of $1120 \pm 110$ (NUTA-3515), while the sediment at $11.35-11.45 \mathrm{~m}$ produced an age of only $890 \pm 110$ (NUTA-3011). Also, either the date of $9510 \pm 160 \mathrm{BP}$ (NUTA-3516) at $17.90 \mathrm{~m}$ is much too old, or the basal date of $9130 \pm 170 \mathrm{BP}$ (NUTA3012 ) at $20.5 \mathrm{~m}$ is much too young. Tentative initial acceptance of the basal date was based on the opinion that the basal $15 \mathrm{~cm}$ of darker consolidated sediment could represent the end of the Pleistocene (Flenley 1996). On the other hand, once pollen analysis was complete, sustained peaks of Poaceae and Asteraceae (Tubuliflorae) for approximately $1.5 \mathrm{~m}$ below the depth, dated at $9510 \pm 160 \mathrm{BP}$, suggests that the depth of $18.0 \mathrm{~m}$ to $18.5 \mathrm{~m}$ could represent the Pleistocene-Holocene boundary. Both Poaceae and Asteraceae (Tubuliflorae) have a preference for cooler/drier conditions. Peaks of cool/dry preference taxa are also present in the other pollen diagrams from Easter Island, some of which date well into the Pleistocene with basal ages of 34,000 BP. It was thought that if the date at $20.50 \mathrm{~m}$ was too young, then this was probably due to incorporation of younger carbon. AMS dating of pollen concentrates was considered an ideal solution to the quandary, as this method gave us the opportunity to remove inwashed and aerially-derived contaminants.

The ${ }^{14} \mathrm{C}$ age estimates from the 3 fractions at the $18.3 \mathrm{~m}$ depth are statistically identical. In contrast, the ages from the 3 fractions at the $16.8 \mathrm{~m}$ depth vary considerably. The coarse plant fragments sieved from $16.8 \mathrm{~m}$ are about $1800 \mathrm{yr}$ younger than the density fractions. Of the 2 density fractions, the 1.3 specific gravity ( $\mathrm{sg}$ ) fraction (visually identified as containing palynomorphs) was older than the 1.25-sg fraction which contained fine plant fragments. Although the difference is not as great as with the large plant fragments, when the ages of the 2 fractions are calibrated, they do not intersect at the $2-\sigma$ confidence interval. Initially, there seemed no obvious explanation for why the large plant remains should be so much younger than the pollen in one depth but not the other.

The date from $18.30 \mathrm{~m}$ of $8477 \pm 60 \mathrm{BP}$ (NZA-11641) was not that much younger than the NUTA3516 date of $9510 \pm 160 \mathrm{BP}$ obtained previously, which seems to give reasonable confidence in the age of this depth. Some $2 \mathrm{~m}$ of sediment separates these 2 depths $(18.3 \mathrm{~m}$ and $17.9 \mathrm{~m})$ from the basal (20.5 m) age of $9130 \pm 170 \mathrm{BP}$ (NUTA-3012), yet very little difference in age is seen. This led us to question whether the basal date at $20.5 \mathrm{~m}$ of $9130 \pm 170 \mathrm{BP}$ (NUTA-3012) was too young (see Table 1). The pollen evidence showing peaks of cool preference taxa below the $18.0 \mathrm{~m}$ to $18.5 \mathrm{~m}$ depth would suggest this basal date was too young.

Four additional ages using AMS on extracted pollen were obtained from the 1.29-1.315, 2.15-2.25, $13.40-13.425$, and $20.35-20.40 \mathrm{~m}$ depths. It was hoped that these would clarify the basal date of the lake sediment and establish a chronology for the floating mat. The pollen concentrate density fraction 
was the only fraction dated for these 4 samples. The basal age of the lake sediment was given some confirmation when a date from $20.40 \mathrm{~m}$ of $8726 \pm 65$ BP (NZA-15464) was returned. Previously, only 1 bulk sediment date had been obtained from the base $(2.90 \mathrm{~m})$ of the floating mat, $1120 \pm 110$ BP (NUTA-3515). The 2 pollen samples submitted from the floating mat returned ages which seemed the inverse of what we expected. The sample from 2.20 m produced an age of $1965 \pm 70 \mathrm{BP}$ (NZA-15462) and the sample from $1.30 \mathrm{~m}$ an age of $5753 \pm 60 \mathrm{BP}$ (NZA-15461). The middle of the mat appeared to be older than the bottom, giving the appearance that the mat had flipped over. Despite the field team witnessing the inversion of 1 mat, this explanation was considered unlikely based on the pollen evidence. Had the mat been subject to inversion/s, the pollen evidence would not give the characteristic profile of large numbers of tree pollen at the base continuing up the profile to $2.2 \mathrm{~m}$ where tree pollen shows a saw-toothed decline and ultimately disappears $35 \mathrm{~cm}$ from the top (see Figures 2 and 3 ).

\section{DISCUSSION}

With such a pattern of seemingly contradictory dates, we considered possible sources of contamination. In-wash of old carbon from the inner walls of the crater is unlikely to be a major contaminant, as the core site was $300 \mathrm{~m}$ out from the eastern edge of the crater lake. Airborne contamination of mineral and/or organic dust or charcoal from old trees or peat was a possibility. Since most of the samples dated were pollen extracts, it was easy to analyze microscopically both the constituent parts being dated and the residues from separations. Mineral particles are removed from the sample during preparation with the particles smaller than $10 \mu \mathrm{m}$ being removed during sieving and the larger mineral particles being removed during density separation. When present in a sample, charcoal particles were removed at specific gravities of 1.6 to 1.4 . The pollen fraction dated was at specific gravity 1.2 and only contained pollen, spores, and small pieces of plant material. These sediments are not rich in palynomorphs; pollen and spores made up $<20 \%$ of the sample which was dominated by small, light plant fragments. The idea of humic acids moving freely through the profile was also considered, but this is unlikely as a source of contamination as these would have been removed by alkali washes during pretreatment. We then considered the possibility that the source of contamination might be depleted $\mathrm{CO}_{2}$ emitted from the caldera and entering the plant during photosynthesis (Pasquier-Cardin et al. 1999).

To test this hypothesis, we had originally planned to ${ }^{14} \mathrm{C}$ date a sample of the living reed currently growing in Rano Kao, and perhaps a water sample. Unfortunately, that was not possible at the time of this study, so we decided to test the age of the material at the surface of the floating mat. We dated 3 fractions from the top $7.5 \mathrm{~cm}$ with the expectation that sample material from this depth should be somewhere between 0 and $150 \mathrm{yr}$. The ${ }^{14} \mathrm{C}$ age measured for the bulk sample was $312 \pm 40 \mathrm{BP}$ (NZA-18033). The 1.2-sg fraction which contained pollen, spores, and small plant fragments produced an age of $824 \pm 40 \mathrm{BP}$. These 2 dates are significantly older than expected, especially the treated sample containing the smaller plant remains. Even the fraction of sieved plant fragments $>100$ microns returned an age greater than would have been expected for plants presumably growing after 1965 and enriched with bomb carbon (Table 1).

The variability in ages among different fractions separated from the same sediment depth suggests the situation may be even more complex. The inconsistency in age between the 2 fractions separated from the $0-7.5-\mathrm{cm}$ level of the floating mat $(191 \pm 40 \mathrm{BP}$ for the plant fragments sieved out at 100 microns and $824 \pm 40 \mathrm{BP}$ for the fine material collected at $1.2 \mathrm{sg}$ ) suggests that at least 2 components of very different ${ }^{14} \mathrm{C}$ ages combine to make up the bulk of the material collecting in the floating mat. The "bulk sediment" age can be explained as a mixture of the 2 components. It would 
require only about $20 \%$ input of a component aged $824 \mathrm{yr}$ to shift the apparent ${ }^{14} \mathrm{C}$ age of a $191-\mathrm{yr}$ component into the $300-y r$ range.

The variation in ages among different fractions obtained for the top $7.5 \mathrm{~cm}$ is also seen in the deeper lake sediments at $16.8 \mathrm{~m}$. Coarse plant remains $>1 \mathrm{~mm}$ sieved from the sediment at the beginning of the pollen separation procedure yielded a CRA that is significantly younger than the fine fractions separated at specific gravities of 1.3 and 1.25. Even the 2 specific gravity fractions produced CRAs that differ by more than $2 \sigma$ (Figure 4 and Table 1). This pattern is not repeated though at $18.30 \mathrm{~m}$, where the large plant remains and 2 fractions from 1.35 and 1.30 specific gravities yield statistically identical ages.

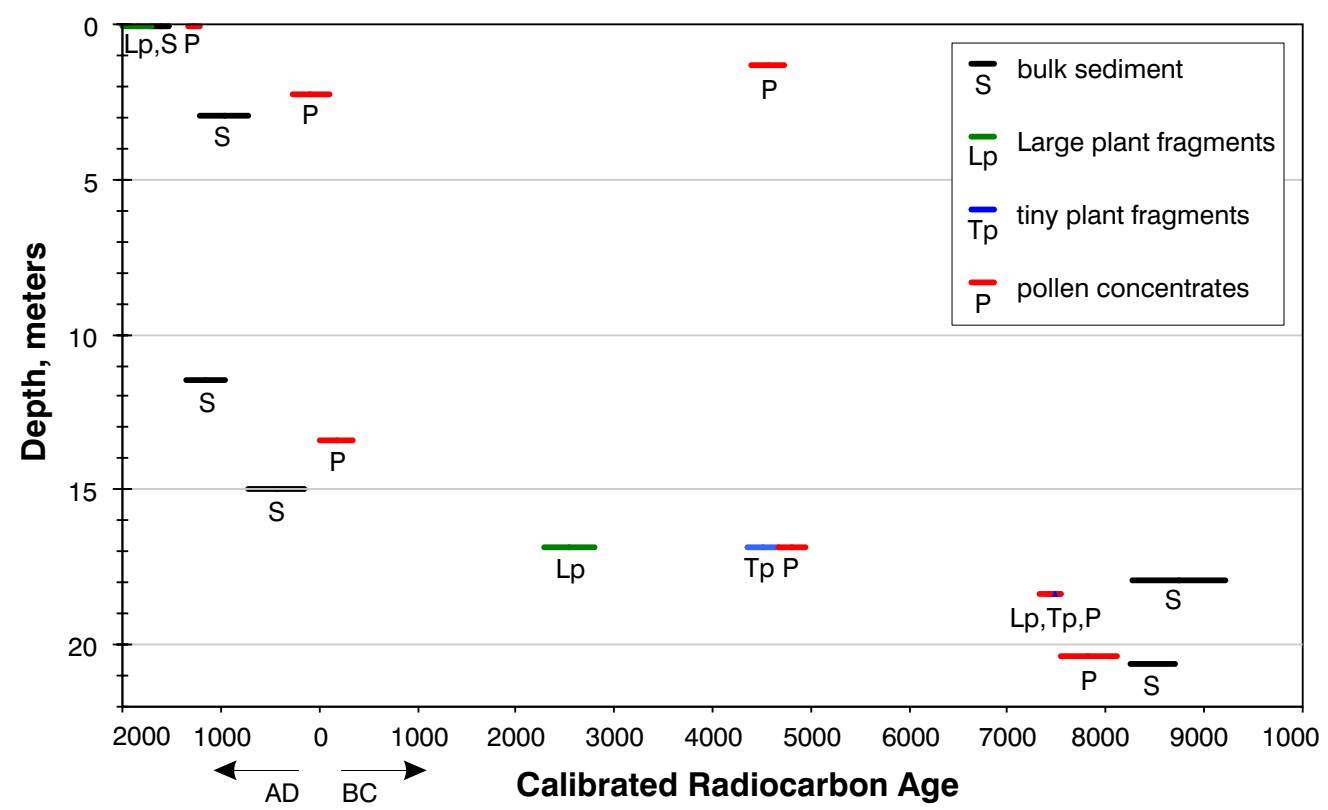

Figure 4 Calibrated ${ }^{14} \mathrm{C}$ ages versus depth diagram for all dated fractions of the Rano Kao 2 core. Length of bar represents $2 \sigma$ confidence interval.

What remains to be explained is the origin of the "old" component. Some possibilities include the following:

- Fine charcoal particles derived from the burning of aged trees outside the crater: There is much evidence for this burning (e.g. Mieth and Bork 2003). The older small plant fragments dated with the pollen do not appear to contain any charcoal. Microscopic analysis of the dated samples has shown no charcoal present, although charcoal may be a factor in the "bulk sediment" ages.

- Depleted $\mathrm{CO}_{2}$ emitted as gas from the caldera floor and incorporated by photosynthesis: Depleted volcanic $\mathrm{CO}_{2}$ alone does not seem to provide an explanation for these anomalously old ages, but there are some indications that it could be a factor. This will be tested by ${ }^{14} \mathrm{C}$ dating live-collected plants and determining their apparent age. It is possible that depleted $\mathrm{CO}_{2}$ is being emitted in varying quantities over time. The 2 fractions (small plant fragments and $>100-\mu \mathrm{m}$ plant fragments) differ in age considerably, and this would require a different source for each to produce such an anomaly. If variably-depleted $\mathrm{CO}_{2}$ contributes to ${ }^{14} \mathrm{C}$ age variability, it may be necessary to date live-collected plants from both the middle of the crater and from the edge to 
ascertain whether emissions are spatially variable within the crater, as well as water sourced from different locations within the lake.

- Periodic droughts leading to lowering of the lake level and erosion of the marginal sediments: There is, however, currently no evidence for such droughts. Although there are occasional droughts on the island, they are not severe or long lived. Droughts due to ENSO are unlikely, as the island is on the fulcrum between the ENSO extremes of the East and West Pacific (Genz and Hunt 2003; MacIntyre 2001). Inside the caldera, it is quite sheltered from wind, but it is possible that during drought years older small plant fragments are blown from the edge out into the center areas and then incorporated into the floating mats. Placing modified pollen traps onto the floating mats, and/or onto the open water between the floating mats, to catch any small plant fragments may be worthwhile. Biological identification of the small plant fragments would greatly assist in identifying possible source areas.

Additional coring of Rano Kao and Rano Raraku, plus the collection of water and of living material from these sites, is planned for later in 2004. Our research design for sampling will incorporate testing of each of these possibilities.

\section{CONCLUSION}

The floating mats seem to be quite complex and their reliability as chronological indicators or archives of vegetational change may be in question. Pollen evidence would seem to rule out the inversion of the floating mats. The possibility that these mats have been inverted, or "flipped over," on more than one occasion in the past cannot, however, be ruled out. Whilst there is evidence of variable age with both young and old components in 1 sample, the lake sediment ages produce a more regular pattern of increasing age with depth. Further analysis and interpretation is needed in order to correlate the Rano Kao lake sediment with that in Rano Raraku. Some anomalies are also apparent with the SURRC "bulk sediment" dates of the Rano Raraku lake sediments (Flenley et al. 1991). Component-specific AMS dating of different fractions from the Rano Raraku sediments may also produce variable ages of both younger and older components.

Future research will include the ${ }^{14} \mathrm{C}$ dating of live-collected samples of the plants living within the craters of Rano Kao and Rano Raraku to determine whether depleted $\mathrm{CO}_{2}$ in the lake water contributes to anomalously old ages and, if so, to what degree. Additionally, small plant fragments will be identified to help determine their source of origin. In the meantime, we regard bulk sediment ${ }^{14} \mathrm{C}$ ages in this region with some degree of caution.

\section{REFERENCES}

Bahn P, Flenley JR. 1992. Easter Island, Earth Island. London: Thames \& Hudson. 240 p.

Butler K, Flenley JR. 2001. Further pollen evidence from Easter Island. In: Stevenson CM, Lee G, Morin FJ, editors. Pacific 2000: Proceedings of the Fifth International Conference on Easter Island and the Pacific. p 79-86.

Flenley JR. 1996. Further evidence of vegetational change on Easter Island. South Pacific Study 16(2): $135-41$.

Flenley JR. and Bahn P. 2003. The Enigmas of Easter Island. Oxford: Oxford University Press. 256 p.

Flenley JR, King ASM, Teller JT, Prentice ME, Jackson J, Chew C. 1991 The Late Quaternary vegetational and climatic history of Easter Island. Journal of Quaternary Science 6(2):85-115.

Genz J, Hunt TL. 2003. El Niño/Southern Oscillation and Rapa Nui prehistory. Rapa Nui Journal 17(1):7-14.

Hunter-Anderson RL. 1998. Human vs climatic impacts at Rapa Nui. In: Stevenson CM, Lee G, Morin FJ, editors. Easter Island in Pacific Context: South Seas Symposium. Proceedings of the Fourth International Conference on Easter Island and East Polynesia. Easter Island Foundation, Bearsville \& Cloud Mountain Press: California. p 85-99.

Jowsey PC. 1966. An improved peat sampler. New Phytologist 65:245-8.

McCall G. 1993. Little Ice Age: some speculations for 
Rapa Nui. Rapa Nui Journal 7(4):65-70.

MacIntyre F. 2001. ENSO, climate variability, and the Rapanui, Part II. Oceanography and Rapa Nui. Rapa Nui Journal 15:83-94.

Mieth A, Bork H-R. 2003. Diminution and degradation of environmental resources by prehistoric land use on Poike Peninsula, Easter Island (Rapa Nui). Rapa Nui Journal 17(1):34-41.

Pasquier-Cardin A, Allard P, Ferreira T, Hatté C, Coutinho R, Fontugne M, Jaudon M. 1999. Magmaderived $\mathrm{CO}_{2}$ emissions recorded in ${ }^{14} \mathrm{C}$ and ${ }^{13} \mathrm{C}$ content of plants growing in Furnas caldera, Azores. Journal of Volcanology and Geothermal Research 92: 195-207.

Prior CA, Chester PI. 2001. Precision radiocarbon dating of a Late Holocene vegetation history. In: Jones M,
Sheppard P, editors. Australasian Connections and New Directions: Proceedings of the 7th Australasian Archaeometry Conference Auckland: University of Auckland, Research in Anthropology and Linguistics series, volume 5. p 285-94.

Stuiver M, Polach HA. 1977. Discussion: reporting of ${ }^{14} \mathrm{C}$ data. Radiocarbon 19(3):355-63.

Stuiver M, Reimer PJ, Bard E, Beck JW, Burr GS, Hughen KA, Kromer B, McCormac FG, van der Plicht J, Spurk M. 1998. INTCAL98 radiocarbon age calibration, 24,000-0 cal BP. Radiocarbon 40(3):104183.

Vandergoes MJ, Prior CA. 2003. AMS dating of pollen concentrates - a methodological study of late Quaternary sediments from South Westland, New Zealand. Radiocarbon 45(3):479-91. 